\title{
Servicios públicos y actividad económica privada y pública en el ámbito municipal
}

\author{
Julia ORTEGA BERNARDO \\ Profesora Titular de Derecho Administrativo \\ Universidad Autónoma de Madrid
}

Palabras clave: servicios públicos; actividad económica; Derecho de defensa de la competencia; ayudas públicas.

Keywords: public services; economic activity; Competition Law; Regional Autorities for competition's Law enforcement; state aids.

SUMARIO: I. INTRODUCCIÓN.-II. DERECHO DE LA COMPETENCIA Y ACTIVIDADES DE LOS AYUNTAMIENTOS: 1. Sobre la disputa competencial entre la Comisión Nacional de la Competencia y la Agencia Catalana de la Competencia para conocer del asunto relativo a la Assemblea Nacional Catalana $(\mathrm{ACN})$ y su campaña para favorecer el consumo (público y privado) de los bienes y servicios de ciertas empresas. 2. Doctrina sobre la aplicación de la legislación de defensa de la competencia a las entidades locales: su concreción en materia de acreditación de profesionales. 3. Sobre las infracciones de la competencia en procesos de licitación pública en el ámbito de las autorizaciones administrativas. 4. Sobre las infracciones de la competencia en procesos de licitación pública en el ámbito de la contratación pública. 5. Presuntas infracciones de la legislación de la competencia en los servicios metropolitanos de suministro de agua. 6. Sobre la exclusividad de la prestación del servicio de clases de esquí derivada de la concesión municipal relativa al uso privativo de un monte de dominio público. 7 . Sobre el servicio de notificaciones administrativas y su posible contratación de terceros por un ayuntamiento para prestarlo.-III. REGULACIÓN DE LOS SERVICIOS FUNERARIOS QUE SE PRESTAN EN EL MUNICIPIO POR PARTICULARES.-IV. SERVICIOS PÚBLICOS LOCALES: 1. Prestación local de servicios sociales. 2. Servicio público de recogida y tratamiento de residuos. 3. Servicio público de suministro de agua.-V. ACTIVIDAD SUBVENCIONAL Y AYUDAS PÚBLICAS EN GENERAL: 1. Ayudas dirigidas a municipios con la finalidad de promover la contratación temporal de desempleados inscritos en una única Comunidad Autónoma. 2. Ayudas reguladas en Ordenanza de concesión de subvenciones dirigidas a menores de dieciséis años, a condición de que se utilice el euskera. 3. Las permutas realizadas por el Ayuntamiento de Madrid y el Real Madrid no se consideran ayuda de Estado-VI. INICIATIVA LOCAL EN LA ACTIVIDAD ECONÓMICA: 1. Régimen de los servicios turísticos de transporte urbano: sometidos a autorización administrativa y limitada su prestación a un único operador. 


\section{INTRODUCCIÓN}

Durante el año 2020 nos encontramos con numerosos pronunciamientos de los órganos y organismos en materia de defensa de la competencia que inciden en el ámbito de actuación de los ayuntamientos. Aunque muchos de ellos no sean condenatorios y los expedientes acaben con el archivo de las actuaciones, declarando que las conductas municipales no resultan infractoras de la legislación de defensa de la competencia, cabe apreciar un aumento de las denuncias por supuestas actividades amparadas o promovidas por los ayuntamientos y contrarias a la libre competencia. También en las sentencias judiciales se va viendo una apertura hacia ese enfoque de promoción de la libre concurrencia empresarial con respecto a los servicios que se prestan en el ámbito local. La literatura científica se ha hecho asimismo eco de esta apertura, aunque también continúa el análisis y la reflexión sobre los temas clásicos en este ámbito. En los últimos meses resulta asimismo de especial interés comprobar la trascendencia jurídica, no exenta de controversia, de la prestación de nuevos servicios en el ámbito municipal, como es el caso de los patinetes eléctricos o del servicio de transporte turístico urbano.

\section{DERECHO DE LA COMPETENCIA Y ACTIVIDADES DE LOS AYUNTAMIENTOS}

\section{Sobre la disputa competencial entre la Comisión Nacional de la Competencia y la Agencia Catalana de la Competencia para conocer del asunto relativo a la Assemblea Nacional Catalana (ACN) y su campaña para favorecer el consumo (público y privado) de los bienes y servicios de ciertas empresas}

Sobre esta cuestión se pronuncia el Dictamen de la Junta Consultiva en materia de conflictos de 31 de enero de 2020, REF. CNMC: 177 CAT 06-36-19 CAMPAÑA CONSUMO ESTRATÉGICO, REF. ACCO: AC 118/2019 - CONSUM ESTRATÈGIC ANC, emitido conforme a lo dispuesto en el art. 2.1, párrafo 5. ${ }^{\circ}$, de la Ley 1/2002, de 21 de febrero, de coordinación de las competencias del Estado y de las Comunidades Autónomas en materia de la competencia. En él se aborda la cuestión de cuál es la autoridad competente para conocer y resolver el expediente relativo a la campaña que desarrolló la Assemblea Nacional Catalana (ACN) para favorecer que particulares y Administraciones locales contrataran servicios y bienes exclusivamente a ciertas empresas, aquellas afines a la causa independentista y que operasen en Cataluña. La Agencia Catalana de la Competencia alegaba al respecto que le correspondía la competencia para investigarlo y decidir sobe el mismo en la medida que su eventual efecto alterador de la competencia se producía fundamentalmente en territorio catalán. La CNMC consideraba, por su parte, que ella debía asumir el ejercicio de la competencia sobre ese asunto en la medida que las 
empresas inscritas en el buscador de empresas afines de la ACN operaban muchas de ellas en territorio nacional. Finalmente se considera que la competencia le corresponde a la CNMC en la medida que la conducta puede calificarse como susceptible de afectar a la unidad del mercado. Así, se considera que esta conducta realizada por la ACN está dirigida a limitar, si no a excluir, tanto el ejercicio por las empresas, afectadas por la no inscripción, de su actividad económica en una parte significativa del territorio nacional, como la libre circulación de los productos y servicios de dichas empresas. Ello se quiere conseguir a través de impulsar su discriminación por razones ideológicas, ajenas a la lógica del mercado. Se dice en el referido Dictamen que, como consecuencia de tal discriminación, se quieren obtener ventajas económicas para las empresas no afectadas, incluso en lo que respecta a la adjudicación de contratos públicos por parte de los Ayuntamientos.

\section{Doctrina sobre la aplicación de la legislación de defensa de la competencia a las entidades locales: su concreción en materia de acreditación de profesionales}

Con respecto a la aplicación de las Administraciones públicas al Derecho de la competencia, la Resolución de la Comisión de Defensa de la Competencia de la Comunidad Valenciana de 13 de enero de 2020, expediente SAN 2/2018, se pronuncia al hilo de una denuncia dirigida contra el Ayuntamiento de San Juan de Alicante. Al Ayuntamiento se le acusa de una supuesta infracción de la legislación de la competencia al exigir sucesivos certificados acreditativos de la competencia de los ingenieros superiores de minas para emitir certificados de segunda ocupación de viviendas, actuación que supondría una limitación de competencia que privilegia a arquitectos y arquitectos técnicos.

Se reconoce en la referida resolución que la competencia o capacitación profesional de determinados profesionales para realizar informes de evaluación de edificios o certificar el estado de conservación y habitabilidad de las edificaciones de carácter residencial se ha suscitado en varias ocasiones ante la Comisión de Defensa de la Competencia de la Comunitat Valenciana en el ámbito de la Ley 15/2007, de Defensa de la Competencia (en adelante LDC). En este sentido pueden verse, por ejemplo, expediente SAN 3/2015, Colegio de Aparejadores y Arquitectos Técnicos de Alicante; expediente PROM 10/2015, Certificados para obtención de licencias de segunda ocupación de viviendas; expediente PROM 2/2016, Ingenieros Industriales Santa Pola; expediente SAN 1/2017, de 11 de enero de 2018. Asimismo, se deja constancia de que la mayoría de estas cuestiones y reclamaciones se han planteado en el ámbito de los arts. 26 y 28 de la Ley 20/2013, de 9 de diciembre, de Garantía de la Unidad de Mercado (en adelante, LGUM). Al hilo de este conflicto, en la resolución también se afirma la sujeción de las Administraciones públicas a la LDC, salvo que la ley haya amparado, a tenor del art. 4.1 de la Ley 15/2007, de Defensa de la Competencia, la conducta restrictiva de la Administración. En este sentido, la resolución cita (apdo. 28) la Sentencia de 18 de julio de 2016 del Tribunal Supremo, y afirma que no hace falta que la actuación de la Administración 
la realice en todo caso con la condición de operador económico. Esta condición de operador económico sí sería necesaria para que se pudiera aplicar el tipo descrito en las conductas de abuso de posición de dominio - art. 2 LDC — o de acto de competencia desleal con afectación al interés público - art. 3 LDC-. Hay que tener en cuenta que esta doctrina jurisprudencial parte de varias premisas, que asume como propias en la resolución la Autoridad valenciana de la competencia. Conforme a ellas se entiende que la sujeción al Derecho de la competencia de una determinada conducta viene determinada ante todo por la capacidad de dicha conducta para incidir en el mercado y restringir la competencia.

Asimismo, aunque se trate de una conducta consistente en una «actividad económica», esto es, se identifique con ofrecer bienes o servicios en un determinado mercado, se admite que la participación del infractor puede darse en diferentes grados y formas, sin excluir las categorías tradicionales del Derecho penal como son el instigador o inductor, el cooperador necesario, etc. Se considera además que la vía impugnatoria frente a un acto o disposición conforme a lo previsto en los arts. 12.3 y 13.2 LDC no excluye otras vías de reacción frente a la actuación administrativa contraria a la legislación de la competencia, sobre todo cuando se trata de actuaciones materiales. Con base en todo ello, la resolución habría de entender que la actuación denunciada del Ayuntamiento no podría ser subsumida en los arts. 2 y 3 porque no se trata de una actuación de un operador económico (condición que considera necesaria para la aplicación de estos preceptos). No lo dice expresamente, pero sí que queda claro en el texto de la misma que la actividad realizada por el Ayuntamiento y objeto de denuncia en este supuesto ha sido una conducta en la que «actúa como regulador en una función típicamente administrativa de intervención cual es la de concesión de autorizaciones y licencias como función de control preventivo en la actividad de los ciudadanos».

En cualquier caso, la resolución de la Autoridad valenciana valora si resultan de aplicación los citados arts. 2 y 3 LDC a la actuación municipal, atendiendo a su literalidad. A la conclusión a la que llega tras esta valoración es que no se subsume en el primer supuesto del art. 2 LDC porque claramente se constata que no se trata de una actuación de un operador con dominio de un mercado; tampoco en el segundo (art. 3 LDC), porque efectivamente el Ayuntamiento no actúa como operador económico. Lo descarta así en ambos supuestos. En relación al art. 1 LDC también lo declara inaplicable porque se trata de una actuación unilateral y este precepto requiere que se trate de un acuerdo o actuación bilateral. Siguiendo estas premisas lógicas y sin ir más allá, la resolución considera que la denuncia de la actividad del ayuntamiento ha de ser archivada.

\section{Sobre las infracciones de la competencia en procesos de licitación pública en el ámbito de las autorizaciones administrativas}

En el caso de la Resolución del Tribunal de Aragón de Defensa de la Competencia de 29 de mayo de 2020, expediente 01/2019/COM, Patinetes, se examina el procedimiento 
de licitación seguido por el Ayuntamiento de Zaragoza para el otorgamiento de dos autorizaciones de uso especial del dominio público con la finalidad de explotación de vehículos de movilidad compartida (patinetes). Se considera que podría haberse incurrido en una infracción de la legislación de defensa de la competencia por la posible colusión entre empresas licitadoras.

El Tribunal aragonés de Defensa de la Competencia comienza analizando la competencia municipal sobre el uso de los patinetes. Llega en este punto a la conclusión de que corresponde a los ayuntamientos la regulación de los usos de las vías urbanas, de conformidad con el art. 7.b) del texto refundido de la Ley sobre Tráfico, Circulación de Vehículos a Motor y Seguridad Vial, aprobado mediante Real Decreto Legislativo 6/2015, de 30 de octubre. Asimismo, y dado que la explotación de vehículos de movilidad personal compartida supone una utilización del dominio público municipal que excede del uso común general que corresponde a todos los ciudadanos por igual, las empresas dedicadas a esta actividad empresarial están sujetas a la obtención de la pertinente autorización municipal de uso especial del citado dominio, de conformidad con la normativa reguladora del patrimonio de las Administraciones públicas. Además, de acuerdo con los arts. 8.2.a) de la Ley 17/2009, de 23 de noviembre, sobre el libre acceso a las actividades de servicios y su ejercicio, 92.1 de la Ley 33/2003, del Patrimonio de las Administraciones Públicas, y 80.1 del Reglamento de Bienes, Actividades y Obras de las Entidades Locales de Aragón, aprobado mediante Decreto 347/2002, de 19 de noviembre, del Gobierno de Aragón, el otorgamiento de las autorizaciones se debe efectuar a través de un procedimiento de concurrencia que respete los principios de igualdad de oportunidades, publicidad, objetividad, imparcialidad y transparencia.

Pasa la resolución a plantearse la conformidad a Derecho de la exigencia de obtención de licencias en número limitado. En relación con este aspecto, la Resolución del Tribunal de la Competencia de Aragón considera que puede entenderse, desde la óptica de la libre competencia, como una cierta restricción a la entrada de operadores en el mercado dado que una vez alcanzado el número máximo de autorizaciones permitidas por el ayuntamiento se excluye la entrada de nuevos competidores, de modo que ello produce claramente un cierre del mercado. Se afirma que esta restricción no solo comporta consecuencias negativas para las empresas dedicadas a la explotación de vehículos de movilidad personal compartida, sino también para los usuarios que ven mermadas sus posibilidades de elección entre operadores. Esta menor oferta conlleva que se vea disminuida también su capacidad de forzar un precio por servicio más competitivo, en la medida en que las posibilidades de elección se ven reducidas, y disminuye la capacidad de influencia del consumidor, como demandante, en la fijación de precios. Sin embargo, en este caso concreto, se llega a la conclusión que las especiales características de la actividad de explotación de vehículos de movilidad personal compartida en lo que a la utilización del dominio público se refiere, justifican la exigencia a los operadores de un título habilitante para acceder al mercado como medida de protección de un bien jurídico cuyo uso es común a todos. Con ello se evita la sobreocupación de la vía pública y se vela por el orden público. 
En tercer lugar, la resolución estudia la legalidad de la limitación en el número de operadores. Se reflexiona sobre si esta limitación estaría justificada además de en la necesidad de no sobreocupar la vía pública, en que el servicio resultase accesible y en que sea de fácil uso el servicio, de forma que sea posible identificar y acceder a la ubicación de patinetes eléctricos sin muchas complicaciones por parte de los usuarios. Al mismo tiempo se reconoce que al limitar el número de operadores se busca que la actividad empresarial resulte eficiente, de modo que sea posible cubrir costes con el uso no insuficiente de los patinetes. En definitiva, el mantenimiento del orden público, la seguridad vial y el adecuado uso y aprovechamiento del dominio público son razones que a juicio del Tribunal aragonés de Defensa de la Competencia permiten que se pueda justificar la modulación restrictiva del número de vehículos de movilidad personal compartida. Aun así, el Tribunal aragonés considera que seguramente había sido necesario haber realizado un exhaustivo estudio del mercado de patinetes eléctricos en la ciudad de Zaragoza. En él debería analizarse el número de vehículos en circulación con carácter previo a su limitación y también habría de tomar en consideración la entidad de las empresas que estaban operando en el mercado y la comparativa de precios según empresas, entre otros datos. En este sentido, se alude a la posibilidad de que se hubiera podido optar por un sistema de subasta que hubiera permitido introducir un cierto grado de competencia en el mercado fruto de la rivalidad entre operadores en la adjudicación de las autorizaciones, tal y como reseña el «Informe de Regulación sobre la Regulación municipal de los servicios de bikesharing y motosharing» de la Agencia Catalana de la Competencia.

A la vista de todo ello se insta al Ayuntamiento de Zaragoza para que en la tramitación de futuros expedientes que introduzcan restricciones en el número de operadores autorizados para desarrollar un servicio o actividad pública en el espacio público se incorpore siempre una justificación suficientemente motivada y proporcional a las necesidades de limitación de la oferta, de modo que se garantice en todo caso una competencia real en el mercado.

Finalmente, se decide archivar el procedimiento y no incoar expediente sancionador. Se entiende que no hay pruebas suficientes de la realización de conductas colusorias entre las empresas que concurrieron a la licitación que demuestren, llegado el caso, la infracción de la legislación de la competencia. Se considera que la actuación municipal es conforme a Derecho y garantiza además la libre competencia que se abra la licitación de las autorizaciones cada cierto tiempo. Eso sí, recomienda que la frecuencia, si puede ser, resulte anual y no bienal.

A pesar de llegar a esta conclusión, el Tribunal de la Competencia de la Comunidad Autónoma de Aragón realiza ciertas recomendaciones al Ayuntamiento de Zaragoza en relación con el diseño de los criterios de valoración de selección de los operadores recogidos en el pliego de cláusulas administrativas particulares.

Entre otras cosas, recomienda la sujeción a tasa pública de la obtención de la licencia para la actividad de alquiler de patinetes. Se lo aconseja porque considera que implicaría un incremento de los recursos con los que cuenta la corporación local y se eliminaría 
el agravio comparativo con otras actividades empresariales que realizan un uso especial del dominio público y para las que la obtención de licencia municipal sí está sometida a tasas. El ayuntamiento para el caso enjuiciado había justificado en este caso la exención de la tasa municipal en que se trata de un sistema de movilidad compartida, que favorece la consecución de los objetivos municipales de movilidad sostenible.

Además, el Tribunal recomienda la conveniencia de incluir en futuras licitaciones el precio por servicio como criterio de valoración. Considera que este parámetro no solo aporta objetividad a la evaluación de las proposiciones, sino que además tiene una gran repercusión para el consumidor, dado que la mayor competencia en el mercado en términos de precios redunda en una mayor calidad del servicio y en un precio final más ajustado a la demanda.

Por otro lado, hay que resaltar que en el expediente puede verse claramente reflejado cómo el procedimiento convocado no responde a la necesidad del Ayuntamiento de recibir ningún tipo de servicio o prestación, sino a la necesidad de ordenar el uso especial del dominio público municipal consistente en la explotación, por cuenta e interés de las mercantiles interesadas, de patinetes eléctricos de movilidad compartida. Por esta razón, dicho procedimiento, señala con gran corrección el Tribunal al Ayuntamiento, queda excluido del ámbito de aplicación de la Ley 9/2017, de 8 de noviembre, de Contratos del Sector Público.

Sobre otro supuesto análogo, pero en el que no hay tanta claridad con respecto a su exclusión de la legislación de contratos, se pronuncian en la última anualidad otras resoluciones de distintos órganos de la competencia. En concreto, las siguientes:

La Resolución de 28 de julio de 2020 de la Comisión Autonómica de la Competencia de la Generalitat Valenciana, expediente SAN 1/2018, Ayuntamiento de Gandia Feriantes. En concreto se denuncian por presuntamente contrarios a la competencia los Pliegos de Condiciones Técnicas Particulares establecidos por el Ayuntamiento de Gandía para regir las concesiones administrativas otorgadas por licitación pública como títulos habilitantes de la ocupación del suelo público del recinto ferial "Parc Ausias Marc», con motivo de las fiestas patronales.

En concreto, se establecen, a juicio de los demandantes, en los Pliegos condiciones cláusulas desiguales ante situaciones idénticas para los feriantes del recinto, en atención al tipo de bebidas que comercializan. El dato es que se prohíbe que se instalen feriantes que vendan bebidas alcohólicas, salvo cervezas, a excepción de que se trate de un tipo concreto de instalaciones.

Al valorar el tipo de actividad municipal que desarrolla en este caso, el organismo de defensa de la competencia llega a la conclusión de que el Ayuntamiento de Gandía cuando licita públicamente la autorización para la ocupación de suelo público del recinto ferial no actúa como operador económico en el mercado de actividades feriales, ni tampoco en el mercado más específico de restauración en casetas de recintos feriales. Se afirma que en este caso el Ayuntamiento ejerce una función típicamente adminis- 
trativa de intervención pública, de control preventivo de la actividad particular, la de concesión de autorizaciones y licencias de ocupación del espacio público, de suelo en este caso de titularidad pública destinado a actividades feriales. Debido a esta conclusión, la Autoridad administrativa valenciana resuelve no incoar un procedimiento sancionador de los previstos en la legislación de defensa de la competencia. No obstante, se considera aplicable en este caso (a nuestro juicio de forma incorrecta) y así se cita expresamente la Ley 9/2017, de 8 de noviembre, de Contratos del Sector Público. En este sentido se recuerda que esta legislación refuerza la necesidad de salvaguardar la libre competencia, como uno de los principios inspiradores del proceso de contratación pública. En este caso incluso se considera por parte de la Autoridad de la Competencia que la denuncia encontraría su fundamento en la infracción del art. 132 de la vigente Ley de contratos.

Desde un punto de vista material, la Autoridad valenciana de la Competencia considera que es legítimo y deseable, desde luego, que la actuación administrativa promueva comportamientos o hábitos saludables en la ciudadanía; sin embargo también se afirma que, en la valoración y diseño de los medios por los que ha de procurarse la consecución de estos fines de indudable interés público, debería realizarse un ejercicio de ponderación de la proporcionalidad y adecuación de los medios utilizados, a fin de que las posibles restricciones o limitaciones que se generen sean las mínimas imprescindibles y no existan, por otra parte, otros medios distintos que sean más adecuados para alcanzar el fin de interés público. En otras palabras, no le convence a la Comisión valenciana la resolución de archivo de la actuación administrativa y no incoación de un procedimiento sancionador. Es claro que la actuación municipal no se considera conforme a Derecho, pero al mismo tiempo no se tiene más remedio que concluir, atendiendo a las premisas en las que se basa la resolución, que la misma no resulta contraria a la legislación de defensa de la competencia. En este punto, en el propio pronunciamiento de la Comisión se abre la cuestión de si este tipo de conductas no deberían ser perseguidas por ella misma, como Autoridad de la Competencia por contrarias a la legislación de garantía de la unidad de mercado.

Sobre un supuesto análogo, encontramos la Resolución de 20 de noviembre de 2019 de la Agencia Catalana de la Competencia, núm. de expediente 87/2017, Playas de Palagrugell. En ella sí se concluye con la declaración de la existencia de conductas colusorias prohibidas por el art. 1.1 LDC. Se constata en el expediente la concertación entre empresas independientes realizada en el marco de los procedimientos de licitación pública de las autorizaciones municipales para la explotación de servicios de temporada en las playas y zonas de dominio público del municipio de Palafrugell durante el periodo 2004-2020. Se trata de conductas colusorias realizadas por empresas dirigidas al reparto de mercado mediante un pacto de no agresión para asegurar así el mantenimiento del stat quo territorial, esto es, que las empresas previstas por ellas resultaran adjudicatarias de los lotes acordados previamente en las sucesivas licitaciones públicas del Ayuntamiento de Palafrugell durante el referido periodo de tiempo. 


\section{Sobre las infracciones de la competencia en procesos de licitación pública en el ámbito de la contratación pública}

En este sector de la contratación pública encontramos la Resolución de la Agencia Catalana de la Competencia de 21 de julio de 2020, expediente 100/2018, Aerobuis, acordada ante la denuncia de realización de conductas colusorias probadas en el marco del procedimiento de contratación promovido por el Área Metropolitana de Barcelona para la concesión del servicio público del transporte colectivo urbano de viajeros en autobús.

En este supuesto, como en otros análogos, se pone de manifiesto cómo este tipo de actuaciones restrictivas de la competencia favorecen exclusivamente a las empresas que forman parte del acuerdo y eliminan los beneficios que aporta la libre competencia en detrimento del interés general. Se pone en evidencia con claridad las consecuencias directas de la falta de una auténtica competencia en la contratación pública, tanto por los sobrecostes en el aprovisionamiento público (precio no competitivo, escasa calidad en los bienes y servicios adquiridos, falta de innovación, etc.) como por el fraude y la corrupción. Por esta razón, en resoluciones como esta se enfatiza como objetivo público prioritario conseguir una contratación pública que logre verdaderas tensiones competitivas entre las empresas licitadoras, de manera que se promueva la eficiencia económica, la calidad y la innovación que, de forma agregada, resulta un factor clave para fomentar la productividad y el crecimiento económico.

\section{Presuntas infracciones de la legislación de la competencia en los servicios metropolitanos de suministro de agua}

En relación con los servicios metropolitanos de suministro de agua se pronuncia la Resolución de 17 de diciembre de 2020, núm. de expediente 69/2015, Contadores de agua, de la Agencia Catalana de la Competencia. En este sector del servicio de abastecimiento de agua potable, el art. 66.3 del Decreto Legislativo 2/2003, de 28 de abril, por el que se aprueba el Texto refundido de la Ley municipal y de régimen local de Cataluña y el art. 5 del Decreto Legislativo 3/2003, de 4 de noviembre, por el que se aprueba el Texto refundido de la legislación en materia de aguas de Cataluña, establecen que las competencias relativas al suministro de agua corresponden a las entidades locales, y en concreto, a los ayuntamientos. Ahora bien, estos las pueden delegar en una entidad supramunicipal, que es la fórmula utilizada en la ciudad de Barcelona y en la mayoría de municipios del Área Metropolitana de Barcelona (AMB), según recoge el «Reglamento del Servicio Metropolitano del Ciclo Integral del Agua». De conformidad con los arts. 5, 12 y 125 del «Reglamento del Servicio Metropolitano del Ciclo Integral del Agua», corresponde a la $\mathrm{AMB}$ aprobar las tasas y precios de los servicios derivados del suministro del agua (propuestos por los ayuntamientos o las entidades suministradoras). Posteriormente, estos precios tienen que ser autorizados por la Comisión de Precios de Cataluña. 
En este caso se denuncia contra Aguas de Barcelona, Empresa Metropolitana de Gestión del Ciclo Integral del Agua, S. A. (AB), y Aqualogy Solutions, S. A. (MUSA), por la existencia de un monopolio en la práctica en el mercado de alquiler y mantenimiento de contadores de agua, donde el único actor es MUSA, empresa 100 por 100 propiedad del grupo AGBAR. Se denuncia que AB (participada por AGBAR también) está abusando de su posición de dominio como suministrador único del agua para garantizarse también el monopolio del mercado de contadores.

En relación con el supuesto objeto de denuncia, la gestión del servicio municipal de suministro del agua corresponde a la $\mathrm{AMB}$ y la gestión de la mayoría de municipios de esta área, por un total de 11 , se ha delegado en $A B$, que es una empresa con capital social mixto. De acuerdo con la organización de la prestación del servicio de suministro de agua por parte de $\mathrm{AB}, \mathrm{AB}$ no facilita los contadores de agua a sus abonados ni realiza el mantenimiento, ya que, de acuerdo con el referido Reglamento, la empresa suministradora de agua puede decidir si la propia empresa proporciona el equipo de medida y encargarse de su mantenimiento.

En el expediente se constatan primero los datos relativos a este mercado y se pone de manifiesto, en síntesis, lo siguiente:

El Reglamento establece que para la prestación del servicio de suministro de agua es necesario que los abonados dispongan de un equipo de medida (contador) como elemento indispensable para poder calcular el consumo. Este reglamento también regula las normas generales aplicables a los equipos de medida del agua. Así se establece que la entidad suministradora del agua selecciona los contadores de entre aquellos previamente homologados por el organismo competente, los cuales tienen que estar preparados para la telemedición. Los contadores seleccionados pueden ser adquiridos por parte de los clientes a otra empresa o bien ser proporcionados directamente por la entidad suministradora. En este último supuesto, la entidad suministradora se encargará del mantenimiento y puede cobrar el importe correspondiente por este servicio. En caso contrario, los abonados deberán disponer de un contrato de mantenimiento con alguna otra empresa. Al margen de cuál sea la forma de suministro del contador, el reglamento dispone que la entidad suministradora será la encargada de la instalación, sustitución, manipulación (en caso de que fuera necesario) y retirada de los equipos de contadores.

Después de probar los hechos, examinarlos y valorarlos la Autoridad catalana concluye que no hay razones para la incoación de un procedimiento sancionador. De ello se deriva el archivo de las actuaciones realizadas en relación con los hechos denunciados en relación con estos servicios por no apreciar indicios de infracción de la LDC. Se considera que las conductas denunciadas no constituyen infracción, sino que se amparan en el Reglamento del Servicio Metropolitano del Ciclo Integral del Agua. Se considera que en este ámbito resulta conforme a Derecho que en el caso de los municipios en los que Aguas de Barcelona es la empresa suministradora del agua, sea ella la que realiza la selección de los modelos de contadores y la instalación de los mismos, mientras 
que MUSA le adquiere los aparatos de medida (mediante LOGISTIUM) para después proporcionarlos al consumidor final. La Administración de la competencia afirma en este caso que esta es, sin duda, una estrategia empresarial legítima, aunque en su implementación pueden observarse toda una serie de ineficiencias que provocarían un encarecimiento de los servicios que reciben los consumidores finales. En concreto, estas ineficiencias se pondrían de manifiesto en la existencia de una cadena de intermediarios (LOGISTIUM, MUSA y AB) para el suministro de contadores de agua, siendo que la totalidad de estas empresas pertenecen al mismo grupo empresarial. La secuencia de empresas obliga a que en cada una de las fases se genere valor, y a que esta generación de valor tenga como contrapartida unos mayores precios finales soportados por los consumidores. Así, la segmentación de un servicio entre diferentes empresas permite que el excedente del consumidor se asuma como excedente de los productores (en concreto, el grupo AGBAR).

\section{Sobre la exclusividad de la prestación del servicio de clases de esquí derivada de la concesión municipal relativa al uso privativo de un monte de dominio público}

En relación con la actividad económica de impartición de clases de esquí del monte de Formigal, y la actividad realizada por parte del Ayuntamiento de Sallent de Gállego y una empresa concesionaria (que tiene atribuido por título jurídico administrativo el uso exclusivo del monte de dominio público para clases de esquí desde 1988) se produce una denuncia de supuesto abuso de posición de dominio y competencia desleal por parte de otra empresa de esquí. Sobre esta cuestión se pronuncia la Resolución de 29 de mayo de 2020 del Tribunal de Defensa de la Competencia de Aragón, expediente 4/2019, Escuela de Esquí Kaihopara.

En ella se aborda la cuestión de la aplicación de la legislación de defensa de la competencia a las Administraciones públicas y con respecto a ella se reitera el criterio tradicional de que se las aplica esta legislación cuando actúan como operador económico. A este criterio tradicional se añadiría otro, defendido en una parte de la doctrina académica y aplicado por jurisprudencia reciente. Este segundo criterio es tomado en consideración por el Tribunal aragonés de Defensa de la Competencia, por cuanto permite la aplicación de la legislación de la competencia a aquellos supuestos en los que la Administración lleva a cabo una conducta que no se puede reconducir a la de operador económico e incluso va más allá del ejercicio de sus correspondientes competencias administrativas. Se trata de aquellos supuestos análogos al enjuiciado por el Tribunal Supremo en STS de 18 de julio de 2016 (caso Vinos de Jerez) en los que se afirma que cabe la aplicación de la legislación de defensa de la Competencia y la declaración de responsabilidad por parte de los órganos de Defensa de la Competencia, aunque se trate del ejercicio de poder público o ejercicio de Autoridad. Con respecto a ellos, después de tomarlos en consideración y estudio, el Tribunal aragonés afirma que se dan en la práctica de forma 
minoritaria y que la aplicación en ellos de la legislación de defensa de la competencia ha de ser considerada errónea. Así lo sostiene expresamente en la Resolución que comentamos de 29 de mayo de 2020 del Tribunal de Defensa de la Competencia de Aragón. En síntesis, esta resolución considera que este tipo de supuestos no deberían abordarse con los mecanismos que contiene la legislación de Defensa de la Competencia, a pesar de que entiende que la propia CNMC, el Tribunal Supremo y una parte de la doctrina científica considere que pueden ser afrontados por esta vía. La fundamentación de esta tesis que se opone a lo que se podría denominar como "nueva doctrina", se basa en que el control a Administraciones públicas no está expresamente previsto en la legislación de Defensa de la Competencia. También se basa en el argumento de que este "control, que se ha de ejercer de forma independiente - y cita para ello los arts. 106 y 107 TFUE como ejemplo- sobre las Administraciones públicas, solo pueden verificarlo instancias supranacionales». Este segundo argumento parece ignorar la existencia de un control jurisdiccional «independiente» de la actuación administrativa previsto en la $\mathrm{CE}$ (art. 106.2) y que la independencia es una condición que igualmente se predica de las autoridades nacionales de la competencia conforme a la normativa europea. La última norma aprobada en este sentido, la Directiva (UE) 2019/1, del Parlamento Europeo y del Consejo, de 11 de diciembre de 2018, se dirige justamente a dotar a las autoridades de competencia de los Estados miembros de medios y de mayor independencia para aplicar más eficazmente las normas sobre competencia y garantizar el correcto funcionamiento del mercado interior.

En relación con el asunto material, objeto de la referida resolución del Tribunal Aragonés de Defensa de la Competencia, se estudia minuciosamente el mercado de clases de esquí con datos relativos a otras estaciones y se llega a la conclusión de que en las estaciones donde existe competencia entre empresas que prestan ese servicio, la concurrencia conduce a un abaratamiento de los precios, aunque ello no es directamente proporcional al número de empresas en competencia. También se dice que, aunque solo se hayan estudiado pormenorizadamente los datos de estaciones de esquí del Pirineo aragonés, para examinar el mercado y sus beneficios sobre los consumidores, además de los precios habría que incorporar información sobre otros indicadores como facilidad de acceso a los cursos, modalidades de los mismos y profesionalidad de los profesores. Asimismo, se llega a la conclusión de que el tamaño de la estación está relacionado con el precio de las clases, de modo que en las más pequeñas se cobran precios menores.

En cualquier caso, aunque el Tribunal aragonés de la competencia concluye afirmando que en el régimen de uso de la estación concedido por el Ayuntamiento y en las prácticas de la empresa concesionaria no se aprecia ninguna lesión de la legislación de la competencia, se incorpora la recomendación al Ayuntamiento de abrir el mercado. En este sentido le aconseja que opte por un régimen distinto de concesión que no resulte exclusivo ni excluyente, de modo que se eliminen los aspectos restrictivos de la competencia. 


\section{Sobre el servicio de notificaciones administrativas y su posible contratación de terceros por un ayuntamiento para prestarlo}

El Informe 032/20 de la Comisión de la Competencia Nacional (CNMC), de 4 de junio de 2020, se pronuncia en relación con el servicio de notificaciones del Ayuntamiento de Almería. Se trata de responder a una consulta planteada por el propio Ayuntamiento de Almería en relación con el diseño del procedimiento de licitación para la adjudicación de los servicios postales para las notificaciones administrativas, así como la naturaleza legal de dichos servicios a raíz de recientes resoluciones judiciales. En respuesta a ello la CNMC, de acuerdo con los principios de salvaguardia de la libre competencia y eficiencia en la gestión de los fondos públicos, le pide que realice una interpretación pro competitiva de la LCSP y de la Ley 39/2015 y considere que todos los operadores postales pueden realizar notificaciones administrativas, con las debidas garantías legales, siempre y cuando quede asegurada la constancia de su realización. En concordancia con lo anterior le recomienda que opte por procedimientos abiertos y transparentes de contratación y considere que el servicio de notificaciones administrativas, conforme a la legislación española que regula los servicios postales y transpone la Directiva europea sobre la materia, no entra en el ámbito del servicio postal universal (SPU), tal y como ha sido ratificado por el Tribunal Supremo y las resoluciones de la CNMC.

\section{REGULACIÓN DE LOS SERVICIOS FUNERARIOS QUE SE PRESTAN EN EL MUNICIPIO POR PARTICULARES}

En relación a la regulación de estos servicios funerarios se pronuncia la STSJ 1231/2020, de 8 de mayo, JUR 2020/267684, rec. contencioso-administrativo 37/2018. En ella se declara, en relación con la obligación de transparencia a las empresas prestadoras de servicios funerarios prevista en una ordenanza municipal, que resulta contraria a la seguridad jurídica la sujeción indiscriminada a la legislación de transparencia de todas las empresas funerarias, sin distinguir si son públicas o privadas.

En esta sentencia también se aborda el problema sobre el acceso de terceros operadores al servicio de tanatorio por cuanto esta cuestión había sido objeto de sucesivos diferentes pronunciamientos, tanto en sede de defensa de la competencia como en relación a la impugnación de ordenanzas que abordan dicha cuestión. De hecho, este es un problema que también resuelven SSTSJ de Cataluña núms. 909/2020 y 910/2020, ambas de 28 de febrero, en las que se cita la STS de 10 de diciembre de 2019 (núm. 1689/2019). En esta STS — que confirmaba una anterior del TSJ catalán— se analizaba la prohibición de negativa de suministro de este tipo de servicios y se ponía en relación la referida prohibición con el derecho a la propiedad privada y a la libertad de empresa dentro del marco de las normas de defensa de la competencia. Concretamente se afirmaba que la negativa de suministro puede generar problemas de competencia 
(de hecho, en muchos casos puede llegar a eliminarla) cuando la empresa dominante compite con el operador solicitante en el mercado para el cual el insumo denegado - en este caso, la utilización de la instalación del servicio de tanatorio- es, a su vez, un elemento necesario para prestar el servicio. En este sentido, se llega a la conclusión de que para que el acceso a la prestación del servicio de tanatorio resulte de obligatoria imposición, de modo que su incumplimiento conduzca a que el operador dominante incurra en una conducta abusiva y vulneradora de la competencia, ha de constituir, en la práctica, en un elemento esencial para que la empresa competidora pueda prestar el servicio. Esto significa que la empresa no ha de tener una alternativa real o potencial para obtener ese suministro, para el que no ha de existir un sustitutivo racionalmente viable. Esto sucede, por ejemplo, cuando existe un único tanatorio. De esta explicación se deduce que formalmente no puede imponerse a las empresas que prestan el servicio de tanatorio que den acceso a los competidores, pues no hay precepto legal que lo establezca, y, por tanto, las conductas lesivas de la competencia se reducen a los supuestos en los que no se produce el suministro y además concurre la inexistencia de alternativa real o potencial de otra instalación.

\section{SERVICIOS PÚBLICOS LOCALES}

A nivel general, en la literatura académica publicada en esta última anualidad encontramos contribuciones generales en torno a las cuestiones relativas a los servicios públicos. Así, cabe citar el capítulo sobre esta materia de J. J. MONTERO PASCUAL en el Manual de Derecho local, dirigido por M. Lora-Tamayo Vallvé, pp. 447-466. En relación con la gestión de los servicios públicos cabe mencionar los siguientes artículos de J. A. Chinchilla Peinado, «iDe verdad existe una preferencia por las formas de gestión indirecta frente a la gestión directa en la prestación de servicios por los entes locales?», en J. Guillén Caramés, J. J. LaVilla Rubira y F. J. Jiménez de Cisneros CID (auts.), Los nuevos desafios del Derecho público económico: homenaje al profesor José Manuel Sala Arquer, pp. 359-402, también de E. ARIMANY LAMOGLIA, «Gestión directa y descentralizada de servicios públicos locales: encargo a medio propio o transferencia de competencias», Revista de Administración Pública, núm. 213, pp. 141-178, y, por último, de J. Alemany GarCía, «Los modos de gestión de servicio público en el ámbito local», Revista General de Derecho Administrativo, núm. 53. Sobre una cuestión más específica relativa a los servicios sociales versa la contribución de T. FONT I LLOVET, «La gestión de servicios sociales en el ámbito local: nuevos planteamientos sobre la ciudad y la contratación pública», en L. TOlivar Alas y M. CUeTO Pérez, La prestación de servicios sociosanitarios: nuevo marco de la contratación pública, pp. 21-45.

Sobre el tema de la prestación de los servicios públicos en competencia gira la aportación de R. GALÁN VIOQUE, «La progresiva apertura de los servicios públicos locales a la libre competencia», Revista de Estudios de la Administración Local y Autonómica. Nueva época, núm. 14, pp. 69-87. 


\section{Prestación local de servicios sociales}

La STC 82/2020, de 15 de julio, rec. de inconstitucionalidad 3135/2019, declara conforme a la Constitución la Ley 3/2019, de 18 de febrero, de servicios sociales inclusivos de la Comunitat Valenciana, recurrida por su posible vulneración de la autonomía provincial y la suficiencia financiera de las diputaciones provinciales garantizada en la Constitución (arts. 137 y 142 CE) y la lesión de su configuración legal en la Ley 7/1985, de 2 de abril, Reguladora de las Bases del Régimen Local (LRBRL). En esta nueva ley se preveía que las diputaciones provinciales, en el marco de la planificación de la Generalitat, prestaran asistencia técnica y económica y la supervisión que garantizase a los Ayuntamientos, especialmente a los de menor población, capacidad económica y/o de gestión, el ejercicio de sus competencias en materia de servicios sociales. Esta sentencia, al pronunciarse sobre la previsión de la competencia autonómica de coordinación de las diputaciones, la somete a una serie de condiciones: además de estar específicamente atribuida y suficientemente predeterminada, se exige que la coordinación autonómica responda a la protección de intereses generales o comunitarios. De este modo su intensidad se establecerá en función de la relación existente entre los intereses locales y supralocales o comunitarios en tales asuntos o materias. Procedimentalmente se exige además que la coordinación provincial se lleve a través de la adopción de planes sectoriales en cuya tramitación debe garantizarse la participación de los propios entes locales coordinados con la finalidad de armonizar los intereses públicos afectados.

Con respecto a la autonomía y la suficiencia financiera local, en relación con la vertiente de ingresos (art. 142), la STC referida declara que la autonomía local presupone la existencia de «medios suficientes» para el desempeño de las funciones que la ley atribuye a las corporaciones locales y no necesariamente que los medios sean "propios". En relación a los gastos, la atribución a los entes locales de nuevas tareas, o la ampliación de aquellas que ya venían desempeñando, debe tener como consecuencia, en su caso, la garantía de aquellos ingresos que le permitan hacer frente a la eventual necesidad de gasto que la nueva atribución de competencias pueda suponer. Asimismo, ello comporta la capacidad genérica de determinar y ordenar, bajo la propia responsabilidad, los gastos necesarios para el ejercicio de las competencias referidas.

En aplicación de esta doctrina jurisprudencial, el Tribunal Constitucional considera constitucionales la mayor parte de los preceptos impugnados de la Ley 3/2019 de servicios sociales inclusivos de la Generalitat, sin perjuicio de que se enfatice expresamente la necesidad de que la atribución por parte del legislador sectorial de una nueva competencia o de una nueva función a los entes locales deberá hacerse garantizando su suficiencia financiera. Concretos preceptos legales se consideran, no obstante, nulos, en la medida en que no se adecúan, a juicio del Tribunal, a las exigencias constitucionales para desarrollar la función de coordinación de las diputaciones provinciales que se encuentran a su vez concretada y desarrollada en la normativa básica estatal. Se trata, en especial, de 
aquellas determinaciones legales de la ley valenciana que incumplen con la exigencia relativa a que la potestad de coordinación de la Comunidad Autónoma de la función provincial de asistencia económica a los ayuntamientos se realice a través de planes sectoriales en los que se garantice la participación de los entes locales.

\section{Servicio público de recogida y tratamiento de residuos}

En relación con este servicio de gestión de residuos urbanos ya desde el año 2016 venimos advirtiendo (vid. Informe del Anuario sobre Servicios públicos y actividad económica privada y pública en el ámbito municipal, apdo. III, sobre servicios públicos, epígrafe 3.3.1) que se produce abundante jurisprudencia en relación a las restricciones que este comporta y que se imponen y modulan el ejercicio de la libertad de empresa. En concreto, los tribunales se pronuncian en relación a los condicionantes que han de cumplir dichas restricciones, a fin de que las mismas válidas, cuando se incluyen en las ordenanzas consistan en la imposición de obligaciones relativas a entregar los residuos urbanos no domiciliarios a los sistemas municipales de gestión.

En la última anualidad se pronuncia sobre esta cuestión la STS 1420/2020, de 23 de octubre, RJ 2020/448. En ella se considera que la previsión de la Ordenanza municipal de recogida de residuos y limpieza de espacios públicos del Ayuntamiento de Calvià (Mallorca), que establece la incorporación obligatoria dentro del servicio de gestión municipal de residuos de todos los productores de residuos es conforme a Derecho. Ello se indica porque se considera que está basada en razones de eficiencia y eficacia suficientemente motivadas.

En concreto, la sentencia se detiene en aclarar la interpretación que ha extraerse del art. 12.5.c)2. ${ }^{\circ}$, de la Ley 22/2011, de 28 de julio, de residuos y suelos contaminados. Se considera que este precepto puede interpretarse en el sentido de permitir que la Ordenanza obligue a la incorporación al sistema de gestión de residuos municipal a «todos los productores» de residuos comerciales no peligrosos y los residuos domésticos generados fuera de los hogares de un municipio. En síntesis, la STS aclara en relación al art. 12.5.c)2. ${ }^{\circ}$ de la vigente Ley de residuos que la expresión «en determinados supuestos» del artículo referido implica que la ordenanza municipal viene obligada a detallar, exhaustivamente, los distintos sectores de productores que quedan obligatoriamente incorporados al sistema de gestión municipal, con exclusión de los supuestos no previamente detallados. Al mismo tiempo aclara el Tribunal Supremo que lo que el precepto permite es que la incorporación obligatoria de los sujetos pueda ser singularizada. Por ejemplo, solo para hoteles, o solo para clubs náuticos o solo para determinados tipos de residuos. Pero también se entiende que esa dicción literal del precepto no excluye la posibilidad de que la incorporación obligatoria afecte a todos los productores de residuos ubicados en el municipio, como así acuerda la Ordenanza impugnada. En el caso concreto ello conduce a la inclusión en el sistema público de gestión de los residuos producidos en varios clubs naúticos. Ello es así, además, en la medida que ahora sí se cumple 
con el requisito exigible a la Ordenanza de que contenga la justificación razonada de tal obligatoriedad en el expediente de tramitación de la norma, tal y como se requirió en su momento la sentencia de instancia pronunciada por el TSJ de Baleares. Se incluye en el expediente la motivación en relación con los criterios «de mayor eficiencia y eficacia en la gestión de los residuos» que justificaban la incorporación obligatoria de los productores de residuos al sistema público de gestión.

\section{Servicio público de suministro de agua}

En relación al servicio público de abastecimiento de agua, la STSJ de Andalucía núm. 3364/2020, de 29 de octubre, JUR 2020/363493, declara que la Administración municipal tiene la obligación de prestar el servicio de suministro de agua potable, con base en el art. 18.1.g) LRBRL, que reconoce a los vecinos el derecho a «exigir la prestación y, en su caso, el establecimiento del correspondiente servicio público, en el supuesto de constituir una competencia municipal propia de carácter obligatorio» [apdo. 1.g) del art. 18 LBRL]. Se recuerda además que entre los servicios obligatorios de todos los municipios figura el abastecimiento domiciliario de agua potable [art. 25.2.c) LRBRL]. En relación a esta cuestión, la sentencia trae a colación los precedentes de las SSTS de 17 de julio de 2000 y de 14 de febrero de 1994.

En relación con la gestión del servicio público de suministro de agua, también se pronuncia la STSJ de Andalucía núm. 1640/2020, de 15 de octubre, JUR 2021/35568, rec. de apelación 2332/2018, sobre la ordenada prestación del servicio público de abastecimiento de aguas, en el que no cabe amparar el reconocimiento del derecho a realizar la prestación casi a perpetuidad por parte de la entidad que la realiza. En este caso el litigio sobre la gestión indirecta del servicio público de abastecimiento domiciliario de agua en una urbanización trae causa de un acuerdo del Ayuntamiento de 20 de junio de 1977 que se declara nulo por haberse omitido por completo el procedimiento administrativo previsto (incluido el expediente de contratación) en la legislación entonces vigente, en la Ley de Contratos del Estado. Ya en ese momento el abastecimiento de agua potable a domicilio se declaraba como competencia del municipio [art. 25.2.c) de la Ley de Bases del Régimen Local (LBRL); Ley 7/1985, de 2 de abril], como un servicio público de competencia local que se podía prestar (art. 85.2 LBRL) mediante gestión directa (por la propia entidad local o por organismo autónomo, entidad pública empresarial o sociedad mercantil dependiente de la misma) o indirecta (a través de las distintas formas previstas para el contrato de gestión de servicios públicos en la legislación de contratos administrativos). El Tribunal pone de manifiesto que, en especial en este caso, está en juego el interés público de la mejor prestación de un servicio público de primera necesidad, y la libre concurrencia de todos los posibles interesados a un eventual procedimiento de contratación administrativa para adjudicar la gestión de dicho servicio.

En relación con los servicios de depuración de aguas se pronuncia también la STSJ de Extremadura núm. 249/2020, de 15 de octubre, JUR/2020/339202, rec. contencioso- 
administrativo 165/2019. En esta sentencia, en relación con los servicios de agua se declara que cuando los municipios en ejercicio de su capacidad de decisión en aras de satisfacer los intereses que tienen encomendados optan por un sistema de gestión de sus servicios públicos que requiere el uso por un tercero de las infraestructuras municipales, no se produce una lesión de la autonomía local, sino antes, al contrario, ello es el resultado necesario de su ejercicio. Asimismo, se pronuncia sobre la necesidad o no de acudir a los contratos públicos si hay una prestación que se realiza a través de un Consorcio. Se entiende que ese modo de gestión encuentra cobertura en la llamada contratación «in house providing» con la consecuencia de que no hay necesidad de contratar. Aunque también llega a la conclusión que tampoco se trata de un medio propio, sino que, a través del Consorcio — que tiene la consideración de entidad de Derecho público, con personalidad jurídica propia y diferenciada para prestar servicios de competencia municipal, entre otras en el ciclo completo del agua- se adopta un tipo de colaboración horizontal a través de Convenio. Asimismo, en relación con las dudas sobre la competencia de las entidades locales para la gestión del agua en alta, como bien de dominio público estatal, en todas sus fases, la sentencia se refiere a la aplicación del art. 89 del Real Decreto Legislativo 1/2001 por el que se aprueba el Texto Refundido de la Ley de Aguas, que permite que la titularidad de las concesiones de agua se atribuya a mancomunidades por parte de las Confederaciones Hidrográficas.

\section{ACTIVIDAD SUBVENCIONAL Y AYUDAS PÚBLICAS}

\section{Ayudas dirigidas a municipios con la finalidad de promover la contratación temporal de desempleados inscritos en una única Comunidad Autónoma}

En la STS núm. 614/2020, de 28 de mayo, se declaran conforme a Derecho las bases reguladoras, aprobadas por Orden de la Consejería de Empleo de la Comunidad de Castilla y León, de ayudas dirigidas a municipios con menos de 5.000 habitantes con la finalidad de promover la contratación temporal de desempleados para la realización de obras y servicios. En concreto, se declara válida la condición incluida en las referidas bases de que las personas desempleadas estuvieran inscritas como demandantes de empleo no ocupados en el Servicio Público de Empleo de Castilla y León. Se considera que el requisito de inscripción no resulta contrario a los arts. 14 y 139.1 de la Constitución española ni al art. 8.3 de la Ley 38/2003, de 17 de noviembre, General de Subvenciones.

En este sentido en la sentencia se declara que el objetivo de reducir el desempleo en los municipios de una Comunidad Autónoma que tengan una población menor de 5.000 habitantes es compatible con el principio de igualdad de derechos y obligaciones entre los españoles en cualquier parte del territorio estatal no se considera que entrañe obstáculos a la libre circulación dentro de España. Se trata de una medida que se implanta para cumplir con el principio rector de la política social y económica proclamado por el art. 40.1 de la Constitución de lograr el pleno empleo, y que, por tanto, pueden 
emprender, dentro de sus competencias, las Comunidades Autónomas. No resulta, por tanto, inadecuado ni carente de la necesaria proporción y tampoco se considera que pueda entrar en contradicción con la igualdad.

\section{Ayudas reguladas en Ordenanza de concesión de subvenciones dirigidas a menores de dieciséis años, a condición de que se utilice el euskera}

Sobre este supuesto de una Ordenanza municipal que regula la concesión de subvenciones para actividad dirigida a menores de dieciséis años, siempre y cuando se trate de actividades que se realicen en euskera, bien hablado o bien escrito, se pronuncia la STS núm. 725/2020, de 10 de junio, RJ 2020/1620, en la que se declara nula la citada previsión, por considerarla discriminatoria. Considera la STS referida que lo que se cuestiona no es la promoción de organización de actividades impartidas en euskera, sino el hecho de que en una interpretación sistemática de la norma municipal con ese criterio lingüístico se está imponiendo a los destinatarios finales menores de dieciséis años, de cualquiera de las actividades subvencionadas por el ayuntamiento, el conocimiento del euskera para poder participar en ella. Considera el Tribunal Supremo que ello implica una limitación general de acceso a actividades sufragadas con fondos públicos por criterios lingüísticos que resulta incompatible con la cooficialidad constitucional de lenguas en todo el territorio nacional.

\section{Las permutas realizadas por el Ayuntamiento de Madrid y el Real Madrid no se consideran ayuda de Estado}

La Sentencia del Tribunal General de la UE de 22 de mayo de 2019 sobre el Real Madrid y las permutas con el Ayuntamiento de Madrid (asunto T-791/16) anuló la Decisión (UE) 2016/2393, de la Comisión, de 4 de julio, relativa a la ayuda de Estado concedida por el Ayuntamiento de Madrid al Real Madrid en la que se declaró incompatible con el mercado interior esa ayuda.

En la sentencia el Tribunal afirma que la Comisión no ha demostrado suficientemente que el club de fútbol obtuvo una ventaja que no habría obtenido en condiciones normales de mercado. Esto se derivó del dato de que la Comisión no procedió a valorar las parcelas cedidas en sustitución de determinadas parcelas, sino que se atuvo exclusivamente a los valores mencionados por los que se había optado en el acuerdo transaccional.

Para verificar si la venta de un terreno por parte de una autoridad pública a un particular constituye una ayuda estatal, es necesario que se aplique el principio del inversor privado en una economía de mercado. Ello es así con el fin de determinar si el precio pagado es o no aquel que habría podido fijar un inversor privado actuando en condiciones normales de competencia. Al examinar únicamente el valor de la parcela 
B-32, se probó que la Comisión no tuvo en cuenta todos los aspectos de la operación controvertida y de su contexto. En definitiva, se probó en su Decisión que la Comisión no había demostrado suficientemente que la medida controvertida confiriera una ventaja al demandante. De ello se derivó que no pudiera calificarse la medida controvertida de ayuda estatal en el sentido del art. 107.1 TFUE y que, por consiguiente, se anulase la Decisión impugnada.

\section{INICIATIVA LOCAL EN LA ACTIVIDAD ECONÓMICA}

\section{Régimen de los servicios turísticos de transporte urbano: sometidos a autorización administrativa y limitada su prestación a un único operador}

Sobre los servicios turísticos de transporte urbano se pronuncia la STSJ de las Islas Canarias núm. 228/2020, de 30 de junio, JUR 2020/283341. En ella se declara que es actividad económica municipal el transporte urbano con fines turísticos (actividad de circuito turístico urbano). En este caso se trataba de una prestación de objeto de un contrato licitado por una sociedad mercantil unipersonal de capital íntegramente municipal, la cual actuaba por ello como poder adjudicador y como medio propio del Ayuntamiento de Santa Cruz de Tenerife. Se trata del recurso de apelación interpuesto por una empresa húngara contra la adjudicación del contrato y sus pliegos de cláusulas administrativas y técnicas particulares. La impugnación de la decisión municipal traía causa de considerar que la licitación del contrato a un único operador suponía una limitación a la competencia de las empresas dedicadas al transporte de viajeros y un tratamiento discriminatorio en relación con los operadores establecidos fuera de España.

La decisión sobre el modo de gestión de esta actividad económica no se había dispuesto originariamente en el contrato. De hecho, la competencia para determinar el modo de gestión de esta actividad económica correspondía, a juicio de la sentencia, al Ayuntamiento de Santa Cruz de Tenerife (arts. 85 y 86 de la Ley 7/1985, de 2 de abril, reguladora de las bases de régimen local), que encomendó la gestión respecto al procedimiento de contratación a su sociedad mercantil. En este sentido el tribunal sostiene que no se está ante un servicio público, y mucho menos monopolizado. De ello se deriva que no se impide, en principio, a otras empresas la prestación del servicio en régimen de concurrencia con la actividad municipal. La adjudicación del servicio de circuito turístico mediante un procedimiento de licitación pública que garantiza la libre concurrencia y competencia, así como la calidad del servicio mediante la selección de la oferta económicamente más ventajosa, se considera ajustado a Derecho. Para justificar esta decisión, se afirma que el que se licite el servicio que no atenta contra la libertad de competencia justo por esto mismo, porque al no tratarse, en sentido técnico jurídico, de un servicio público y además al no encontrarse reservado al municipio, por principio, no cabe impedir que otras empresas lo presten. En relación a que se trate de un servicio que haya de prestarse en régimen de autorización y que vaya a ser prestado por un único 
operador económico la declaración que, en síntesis, contiene la sentencia, es que ello excepcionalmente ha de permitirse y que en este caso sí estaría justificado. La fundamentación en la que se basa esta solución parte de considerar que, aunque la Ley 17/2009, que transpone la Directiva de servicios, con carácter general establece que el acceso al ejercicio de una actividad de servicio no debe estar sujeta a autorización previa, sí que lo excepciona. Lo mismo se prevé en los arts. 84 bis y ter LRBRL cuando esté justificado por razones de orden público, salud pública o protección del medio ambiente y estas razones no puedan salvaguardarse mediante la sujeción previa a la presentación de una declaración responsable o de una comunicación.

También cabe, a juicio de la sentencia, e igualmente al amparo de los preceptos citados, una excepción a la libre prestación de servicios a través una imposición de la limitación del número de operadores económicos cuando haya escasez de recursos naturales, utilización del dominio público, existencia de inequívocos impedimentos técnicos o en función de la existencia de servicios públicos sometidos a tarifas reguladas. Siendo esto así se reconoce que la adopción de una medida tan intensa de intervención supone una excepción al sistema de libre competencia, que solo cabe admitir cuando existe un motivo de interés general y se encuentra justificada desde los principios de necesidad y proporcionalidad. En esta línea de argumentación la sentencia trae a colación el informe de la Secretaría del Consejo de Unidad de Mercado de 12 de febrero de 2019 que declara que en este ámbito no existe un servicio público y establece los límites de la intervención de los ayuntamientos. De acuerdo con este informe, la prestación de la actividad de transporte turístico urbano admite excepcionalmente el régimen de autorización en la medida que la actividad requiera el uso de la vía pública, lo exija la necesidad de su compatibilidad con otros usos e intereses y sus efectos negativos como congestión de tráfico y contaminación. Asimismo en la sentencia se declara que con base en el art. 5.1 de la Ley 20/2013, de garantía de unidad de mercado, se "podría entender como razón imperiosa de interés general para intervenir en este mercado la de garantizar la seguridad de las personas usuarias del servicio y de la ciudadanía en general, realizar un control en el acceso al dominio público para los operadores económicos que deseen realizar esa actividad con el objetivo de realizar una ordenación del tráfico o para garantizar la seguridad vial». Asimismo, se considera que los arts. 111 y 112 de la Ley de ordenación del transporte terrestre establecen determinadas limitaciones a la prestación a los servicios de transporte turístico relacionadas fundamentalmente con su incidencia en la prestación de los servicios de transporte regular de viajeros de uso general, que no son de servicio público.

En relación con la limitación del número de operadores se hace también referencia al Informe de 7 de noviembre de 2016 de la CNMC, en el que se señala que no cabe descartar que el transporte turístico urbano exija un número limitado de operadores, ya que se desarrolla en vehículos que, por su tamaño, características y modo de prestación de los servicios, hacen un uso intensivo de la vía pública, ya que este tipo de recurso es escaso y de él se obtiene una rentabilidad singular debida a dicho uso. Por otro lado, se aclara en la sentencia que los Pliegos no requieren el establecimiento previo de la em- 
presa en España, lo que sí sería disuasorio y discriminatorio para entidades extranjeras, como refiere la STJUE de 22 de diciembre de 2010 (C-338/2009, Yellow Cab), que citó la demandante. En esta sentencia se declara que el art. 49 TFUE debe interpretarse en el sentido de que no se opone a una normativa nacional que establezca un requisito de establecimiento si este se exige después de la concesión de la autorización y antes de que el solicitante comience a explotar dicha línea. 